\title{
Charge Transfer Effects in CuO Nanofibers, Observed by EELS and XPS.
}

M Piñón-Espitia ${ }^{1}$, J.A Torres-Ochoa ${ }^{2}$, O Córtazar-Martínez ${ }^{3}$, A Herrera-Gomez ${ }^{3}$, Guillermo HerreraPerez $^{1}$ and M.T. Ochoa-Lara ${ }^{1}$

${ }^{1}$ Centro de Investigación en Materiales Avanzados, Chihuahua, Chihuahua, Mexico, ${ }^{2}$ Universidad Politécnica Juventino Rosas, Santiago de Querétaro, Queretaro de Arteaga, Mexico, ${ }^{3}$ CINVESTAV Unidad Querétaro, Santiago de Querétaro, Queretaro de Arteaga, Mexico

* Corresponding author: manuel.pinon@ cimav.edu.mx

The copper (II) oxide semiconductor $(\mathrm{CuO})\left(\mathrm{E}_{\mathrm{g}}\right.$ of $\left.1.2 \mathrm{eV}\right)$ is one of the materials most studied, due to its photoelectronic, photochemical, thermosolar and semiconductor properties, among others, however, the $\mathrm{CuO}$ as 1D structured material [1], especially as nanofiber shape, has showed a good surface/volume relation, excellent physical properties, easy to produce, etc. Improvement of its properties may be generated by doping $\mathrm{CuO}$, especially with transition metals as Manganese ( $\mathrm{Mn}$ ), providing diluted magnetic semiconductors or changes in electronic properties.

Pure and $\mathrm{Mn}$ doped copper oxide nanofibers (CuO-NFs) at $2.5 \%$, were synthesized by the electrospinning method, based on the literature [2], using a solution of $\mathrm{Cu}$ acetate $\left(\mathrm{Cu}\left(\mathrm{CH}_{3} \mathrm{COOH}\right)_{2} \mathrm{H}_{2} \mathrm{O}\right)$ dissolved in a aqueous solution of PVA (8\%wt). For the doped $\mathrm{CuO}-\mathrm{NFs}, \mathrm{Mn}$ acetate $\left(\left(\mathrm{CH}_{3} \mathrm{COOH}\right)_{2} \mathrm{Mn} 4 \mathrm{H}_{2} \mathrm{O}\right)$ at $2,5 \%$, was added.

The material obtained was calcined at $700^{\circ} \mathrm{C}$, to stabilize the tenorite-type phase of $\mathrm{CuO}$, verified by $\mathrm{X}$ Ray diffraction (XRD, Panalytical XpertPRO model) and by Selected Area Electron Diffraction (SAED, model JEM2200FS). The morphological features, such as size and shape, were analyzed using a HRSTEM, model JSM 7401F. The electronic structure and the charge transfer effects were monitored by EELS (inside an environmental of model Philips CM200 TEM). The acquisition of X-Ray photoemission spectra was done by an ESCALAB 250Xi Thermoscientific TM. The Charge Transfer Effects, both by EELS and XPS techniques were detected, as well as the presence of the chemical species: $\mathrm{Cu}^{1+}, \mathrm{Cu}^{2+}$, and $\mathrm{Cu}^{3+}$ ions.

Fig. $1 \mathrm{a}$ and $\mathrm{b}$ show the XRD patterns for undoped and Mn-codoped (2.5\% wt) CuO-NFs, indexed with powder diffraction file (PDF) No. 80-1268. The crystallite size was determined by the spherical harmonic method in the Fullprof Suite program [2], founding values of $36.1 \mathrm{~nm}$ pure for CuO-NFs and $14.9 \mathrm{~nm}$ for $\mathrm{Mn}$ doped $\mathrm{CuO}-\mathrm{NFs}$. The $\mathrm{d}$ and $\mathrm{f}$ panels show the images of two necklace-type shape for the pure and Mn doped CuO-NFs, respectively. The SAED patterns, showed in e and g, were indexed with the CrysTBox program, PDF No. 80-1268 [3]. Fig. 2 displays (a) the Cu 2p XPS and (b) the L3,2 edges EELS profiles. Three chemical species attributed to $\mathrm{Cu}^{1+}, \mathrm{Cu}^{2+}$ and $\mathrm{Cu}^{3+}$ were elucidated. These results agree with those reported in the literature $[4,5]$. The displacements associated with the charge transfer at the edge of the $\mathrm{Cu}^{1+}$ related to the dopant also are showed [6]. 


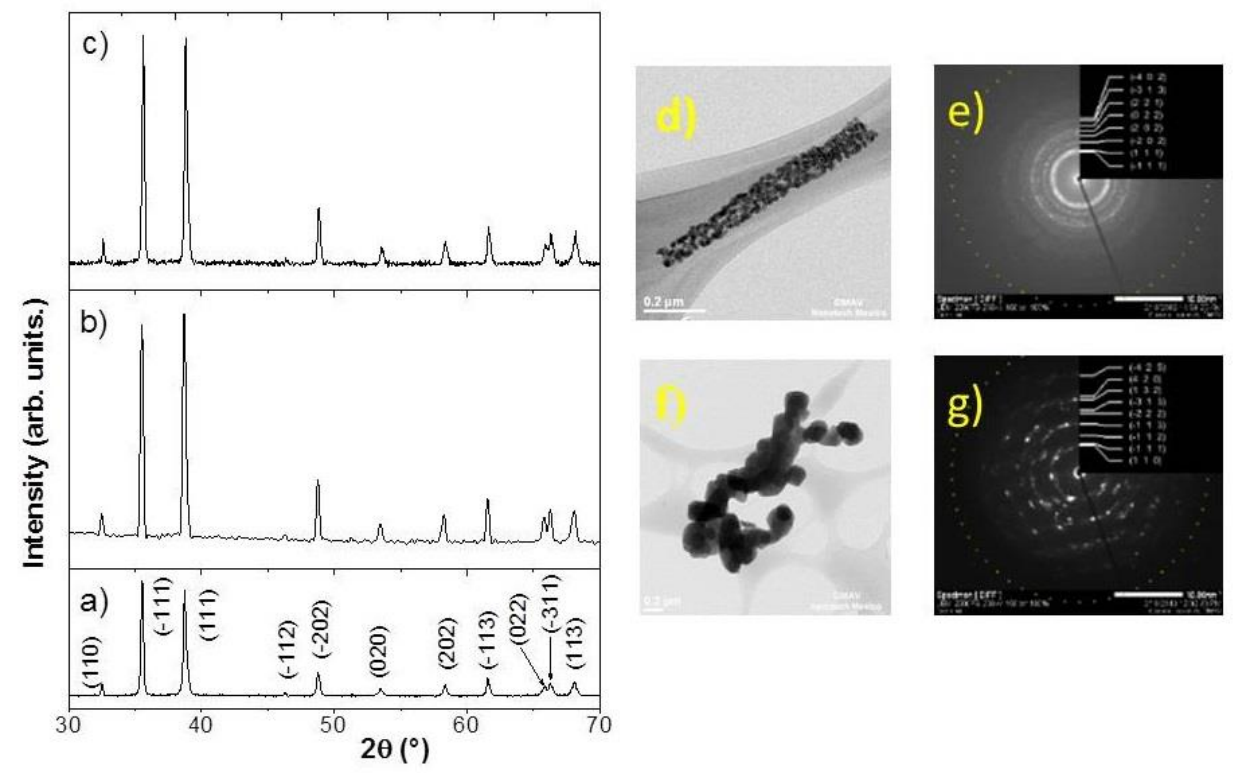

Figure 1. XRD patterns and the refinement of XRD pattern for a) $\mathrm{CuO}-\mathrm{NFs}$, b) $\mathrm{Mn}$ doped $\mathrm{CuO}-\mathrm{NFs}$, c) powder diffraction file; BF-HR-STEM images for d) $\mathrm{CuO}-\mathrm{NFs}$ and f) $\mathrm{Mn}$ doped CuO-NFs. SAED patterns for e) $\mathrm{CuO}-\mathrm{NFs}$, g) $\mathrm{Mn}$ doped $\mathrm{CuO}-\mathrm{NFs}$.

a)

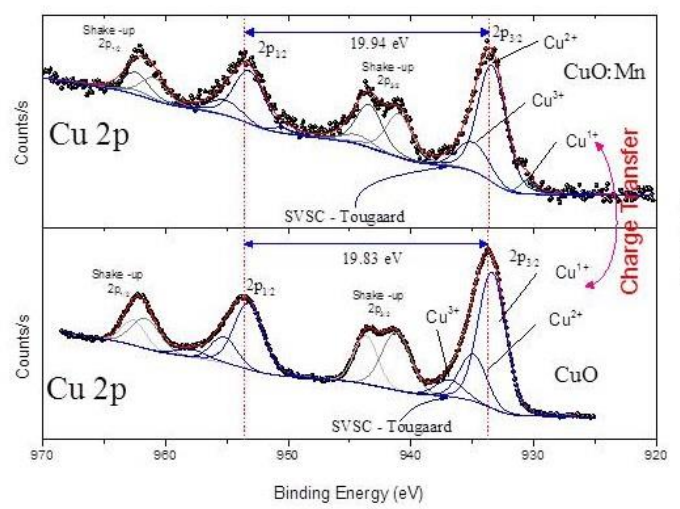

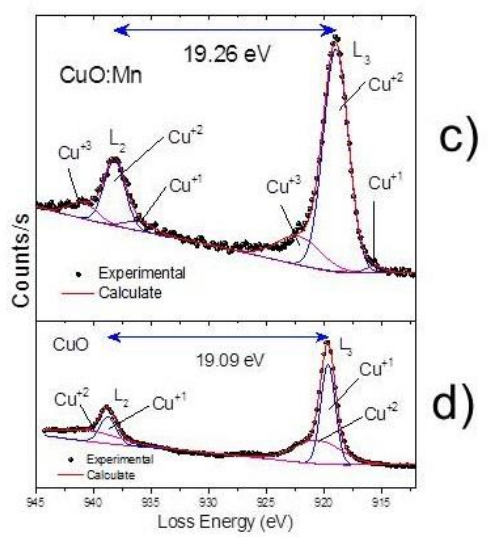

Figure 2. $\mathrm{Cu} 2 \mathrm{p}$ XPS for a) $\mathrm{CuO}$ NFs and b) Mn doped CuO NFs; Cu L2,3-edge EELS for c) CuO-NFs and d) Mn doped $\mathrm{CuO}-\mathrm{NFs}$.

\section{References}

[1] S. Sharma, R. Rani, R. Rai, and T. S. Natarajan, Adv . Mat . Lett. 4 (2013) 749-753.

[2] J Rodríguez-Carvajal, Phys. B Condens. Matter. 192 (1993) 55-69.

[3] M. Klinger, J. Appl. Cryst. 50 (2017) 1226-1234.

[4] J A. Torres-Ochoa, D. F Mulato-Gomez, D. German-Cabrera, M. Bravo-Sanchez, A. HerreraGomez , M. B. S. (2017) 125-126.

[5] M. F Noelia Benito, Phys. Chem. C, 121 (2017) 18771-18778.

[6] M. Piñón-Espitia thanks for the CONACyT grant No. 467043. The authors greatly Luis Gerardo Silva Vidaurri (XPS), C. Ornelas-Gutiérrez (TEM), K. Campos-Venegas (SEM), E. Guerrero-Lestarjette (XRD). 